\title{
Global radiative forcing from contrail-induced cloudiness
}

\section{Ulrike Burkhardt and Bernd Kärcher}

Climate model simulations, evaluated using remote sensing data, estimate the net radiative imbalance of the atmosphere due to aircraft condensation trails and their effects.

Aviation contributes significantly to anthropogenic climate change by emissions of greenhouse gases (mainly carbon dioxide, $\mathrm{CO}_{2}$ ), particles and nitrogen oxides, as well as by changes in cloud level in the upper troposphere. An important but poorly explored component of this contribution is contrail cirrus: the line-shaped condensation trails that form behind cruising aircraft and the irregularly shaped, often long-lived cirrus clouds that evolve from them.

Earlier studies have only estimated the radiative forcing-a measure of the radiative imbalance of the atmosphere-due to linear contrails, ${ }^{1}$ which play a small part in the total climate effect. Spreading trails could not be studied as the methodology relies on the scaling of modeled line-shaped condensation trail coverage to observations inferred from satellite images. Besides the unsuitability of this scaling method for the task, observations of irregularly shaped contrail clouds do not exist because they can hardly, if at all, be distinguished from their natural counterparts. It has thus not been possible to estimate the impact of contrail-induced cloudiness on climate.

We have simulated the climate effect of spreading contrails with ECHAM, a general circulation model of the atmosphere. ${ }^{2}$ Contrail cirrus is treated as a separate class of man-made clouds, ${ }^{3}$ and the physical processes causing their formation, evolution, and decay are parameterized. These man-made clouds evolve in ice-supersaturated regions interacting with the atmospheric moisture field. We calculate their spatial coverage and optical properties (extinction coefficients, effective cloud particle radii, single scattering albedo, asymmetry factor) to evaluate the stratosphere-adjusted radiative forcing. In addition, our study shows that they are capable of reducing natural cloud coverage and optical depth by lowering the water vapor content of the air. We have given the term contrail-induced cloudiness

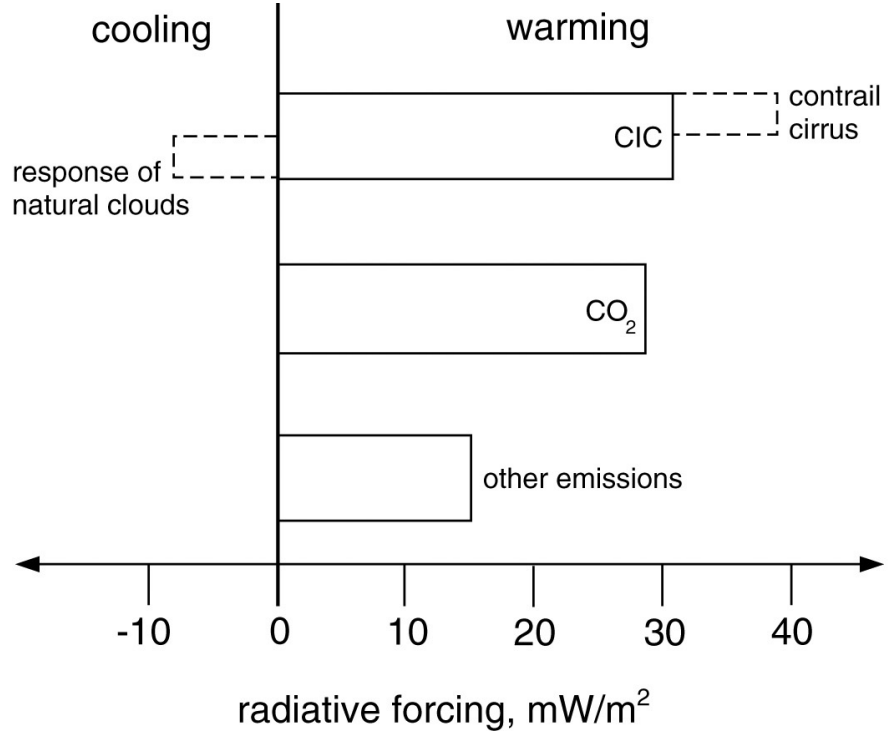

Figure 1. Radiative forcing in the year 2002 from contrail-induced cloudiness (CIC), comprising the direct warming effect of contrail cirrus and the response of natural cirrus clouds introducing a cooling. ${ }^{2}$ For comparison, the radiative forcing from accumulated aviation carbon dioxide $\left(\mathrm{CO}_{2}\right)$ emissions and the net forcing from other aircraft exhaust species (comprising the effect of nitrogen oxide emissions on ozone and methane as well as direct radiative effects from emissions of water vapor and soot particles) are shown for 2005 conditions. ${ }^{1}$

(CIC) to the combined direct radiative effect of contrail and natural cirrus.

An estimate based on an air traffic inventory representative of the year 2002 shows that contrail cirrus exert a direct radiative forcing of $38 \mathrm{~mW} / \mathrm{m}^{2}{ }^{2}$ We further show that these manmade clouds change natural cloudiness, producing an estimated forcing effect of around $-7 \mathrm{~mW} / \mathrm{m}^{2}$. Hence, CIC is the largest component $\left(\approx 31 \mathrm{~mW} / \mathrm{m}^{2}\right.$ ) of aviation-induced radiative forcing (see Figure 1). It more strongly impacts the current climate than all the $\mathrm{CO}_{2}$ emitted by aircraft that has accumulated in the atmosphere since the beginning of modern aviation up to the year 
$2005\left(28 \mathrm{~mW} / \mathrm{m}^{2}\right)$. Besides providing the first estimate of the climate impact of contrail cirrus, our method provides a scientific basis for assessing strategies to reduce this impact.

The uncertainty of contrail cirrus radiative forcing due to the uncertainties in its spreading rate, optical depth and ice crystal shape, and in the radiation parameterization is likely to lie between 10 and 15\%, around 25, 15, and 22\%, respectively. An estimate of the combined uncertainty would need to take into account the interdependence among these different sources. Results from several independent models should be used to assess the radiative forcing due to $\mathrm{CIC}$ and its uncertainty. Finally, to reduce uncertainty, it is important to advance climate models with regard to their representation of processes related to the moisture budget, in particular of cloud processes.

Our results could be useful for studies attempting to reduce the climate impact of aviation either by technological (airframe or propulsion system) or operational means (routing and air traffic management). To do that, it is important to consider the time scale over which aviation climate impact is to be reduced, because short-term perturbations from CIC compete with longterm effects arising from aircraft $\mathrm{CO}_{2}$ emissions. If air traffic were to rise, the contrail cirrus climate impact would stay large. By contrast, a decrease in traffic would diminish the role of contrail cirrus as compared to the effect of accumulated $\mathrm{CO}_{2}$ emissions. Which of these metrics to apply and the related time horizon depend on political and economic constraints.

The evaluation of our simulations is difficult, since observational data sets of contrail cirrus are not available. Instead, we validate the climate model's moisture field, in particular ice-supersaturated areas and line-shaped contrail coverage, using remotely sensed data. Linear contrails have been experimentally characterized with active (ground-based lidar) and passive (space-borne, using solar reflection and IR absorption channels) remote sensing methods. Homogeneous data sets of line-shaped contrail coverage and their optical properties and of ice-supersaturated areas are crucial for further progress. Future work will use such data sets for validation and focus on improving the representation of cloud processes in climate models.
Author Information

Ulrike Burkhardt and Bernd Kärcher

German Aerospace Center

DLR Oberpfaffenhofen, Germany

Ulrike Burkhardt is a research scientist.

Bernd Kärcher is a research scientist.

References

1. D. S. Lee, D. W. Fahey, P. M. Forster, P. J. Newton, R. C. N. Wit, L. L. Lim, B. Owen, and R. Sausen, Aviation and climate change in the $21^{\text {st }}$ century, Atmos. Envir. 43 (22-23), pp. 3520-3537, 2009. doi:10.1016/j.atmosenv.2009.04.024

2. U. Burkhardt and B. Kärcher, Global radiative forcing from contrail cirrus, Nat. Climate Change 1, pp. 54-58, 2011. doi:10.1038/nclimate1068

3. U. Burkhardt and B. Kärcher, Process-based simulation of contrail cirrus in a global climate model, J. Geophys. Res. 114, p. D16201, 2009. doi:10.1029/2008JD011491 